\title{
BMJ Open Night work and prostate cancer in men: a Swedish prospective cohort study
}

\author{
Torbjrn Åkerstedt, ${ }^{1,2}$ Jurgita Narusyte, ${ }^{1}$ Pia Svedberg, ${ }^{1}$ Göran Kecklund, ${ }^{2,3}$ \\ Kristina Alexanderson ${ }^{1}$
}

To cite: Åkerstedt T, Narusyte J, Svedberg P, et al. Night work and prostate cancer in men: a Swedish prospective cohort study. BMJ Open 2017;7:e015751. doi:10.1136/ bmjopen-2016-015751

- Prepublication history is available. To view these files please visit the journal online (http://dx.doi.org/ 10.1136/ bmjopen-2016-015751).

Received 30 December 2016 Revised 27 March 2017 Accepted 13 April 2017

\section{CrossMark}

${ }^{1}$ Department of Clinical Neuroscience, Karolinska Institutet, Stockholm, Sweden ${ }^{2}$ Stress Research Institute, Stockholm University, Stockholm, Sweden

${ }^{3}$ Behavioral Science Institute, Radboud University, Nijmegen, The Netherlands

Correspondence to Dr Torbjrn Åkerstedt; Torbjorn.Akerstedt@ki.se

\section{ABSTRACT}

Objectives Prostate cancer is the most common cancer and the second leading cause of cancer-related deaths among men, but the contributing factors are unclear. One such may be night work because of the day/night alternation of work and the resulting disturbance of the circadian system. The purpose of the present study was to investigate the prospective relation between number of years with night work and prostate cancer in men.

Design Cohort study comparing night and day working twins with respect to incident prostate cancer in 12322 men.

Setting Individuals in the Swedish Twin Registry.

Participants 12322 male twins.

Outcome measures Prostate cancer diagnoses obtained from the Swedish Cancer Registry with a follow-up time of 12 years, with a total number of cases $=454$.

Results Multiple Cox proportional hazard regression analysis, adjusted for a number of covariates, showed no association between ever night work and prostate cancer, nor for duration of night work and prostate cancer. Analysis of twin pairs discordant for prostate cancer ( $n=332$ ) showed no significant association between night work and prostate cancer.

Conclusions The results, together with previous studies, suggest that night work does not seem to constitute a risk factor for prostate cancer.

\section{INTRODUCTION}

Prostate cancer is the most common cancer and the second leading cause of cancer-related deaths among men. ${ }^{1}$ The causes may be age, race/ethnicity and family history, ${ }^{2}$ as well as soy and carrots. ${ }^{34}$ Also firefighters may have an increased risk of prostate cancer. ${ }^{56}$ The latter group is exposed to various carcinogens, but also to shift work, and such work hours interfere with the circadian system, particularly if they involve night shifts. Reviewing epidemiological and experimental literature, the International Agency for Research on Cancer concluded that night work is a probable causative risk of breast cancer in women, that is, placing night shifts in category 2 on the list of causes of cancer. ${ }^{7}$ Furthermore, Kolstad found that the risk of breast cancer was increased after 20 years or more of exposure to night work. ${ }^{7}$ Most, but not all, of subsequent reviews

\section{Strength and limitations of this study}

- Only a few studies have addressed the issue of night work and prostate cancer, and the results are conflicting. The strength of the present study is that it adds a rather large cohort with complete follow-up in national registers.

- A second advantage is that the study also addresses heredity in relation to shift work and prostate cancer.

- A disadvantage is that only subjective information on exposure and covariates is available.

- Another disadvantage is the lack of information on number of night shifts.

have found support for the link between night shifts and breast cancer in women. ${ }^{8-12}$ This link may have important effects on public health since $>18 \%$ of the population in the European Union is exposed to night work (www.eurofound.europa.eu).

In contrast, the association between shift work and prostate cancer has not been clearly established. However, a recent meta-analysis of eight very heterogeneous studies concluded that there is a weak link, ${ }^{13}$ but only three studies show a significant association for 'ever shift work'. ${ }^{14-16}$ Five other studies failed to find a significant association, ${ }^{17-21}$ although the latter did find a significant association in the group with $>28$ years of exposure.

Apart from the involvement of disturbance of circadian rhythmicity in the putative effect of night work on cancer, it is thought that the suppression of melatonin through night-time exposure to light is a contributing factor. ${ }^{22}$ Among the evidence is the finding that blind women have a lower risk for breast cancer than seeing women. ${ }^{23}$ Furthermore, breast cancer growth may be increased by reducing melatonin flow to an implanted tumour in animals. ${ }^{24}{ }^{25}$ Phase advancing light exposure increases the rate of growth of cancer cells in mice. ${ }^{26}$ When light exposure is increased and melatonin is decreased, cancer tumours increase in growth in female rats with implanted cancer tumours. ${ }^{25}$ 
The objective of the present prospective study was to increase knowledge regarding the association between night work and prostate cancer through using data from the Swedish Twin Registry (STR) in which familial factors (genetics and shared environmental) could be taken into account. Hence, a survey question on number of years of night work was used to predict the incidence of prostate cancer.

\section{METHOD}

\section{Design and participants}

The design was a prospective cohort study and is essentially identical to that of a previous study of night shifts and breast cancer in women. ${ }^{27}$ Twins born in Sweden before 1959 who participated in the Screening Across the Lifespan Twin (SALT) study conducted by the STR and who, at the time of the interview, were 41-60 years old were included. Each individual participated in the SALT computer-assisted telephone interview once between 1998 and March 2003. The response rate was $74 \%$, and the total sample encompassed 12322 men. The interview included questions on the duration of night work and a number of items regarding different diseases and symptoms. The procedure for data collection has previously been described in detail. ${ }^{28}$ The individuals were followed prospectively from the interview response date. Data on incident cancer were obtained from two registers at the National Board of Health and Welfare, the Swedish Cancer Registry and from the Cause of Death Register and linked to the twins by using the unique person identification number available for all Swedish citizens. The regional ethical committee of the Stockholm region approved the study.

\section{Variables}

The exposed group was constituted of those who had worked at night for $1-45$ years according to the response to the question: 'For how many years have you had working hours that meant that you worked nights at least now and then'. This group was compared with all others. In addition, further categorisation of exposure was based on intervals in multiples of 5 , with observations that an effect may be expected for $\geq 30$ years or $\geq 20$ years. However, too few cases were obtained for categorisation at $\geq 30$ years, hence the following categorisation was used: $1-5,6-10,11-20$ and $21-45$ years. In total, 4816 male SALT responders had been exposed to night work.

Prostate cancer was defined as having at least one incident cancer diagnosis after the date of the interview, either according to the Swedish Cancer Registry or to the Cause of Death Register.

The following variables were used as covariates: age, educational level $(0=$ compulsory (reference), $1=$ more than compulsory); tobacco use $(0=$ no tobacco (reference), 1=tobacco use (includes current or previous regular smoking/snuffing as well as occasional smoking or snuffing)); alcohol use $(0=$ no alcohol consumption (reference), 1=alcohol consumption); physical activity $(0=$ moderate exercise (reference), $1=$ low exercise, 2=high exercise based on this question in SALT: 'Of these 7 alternatives, which fits your annual exercise pattern?'); body mass index (height ${ }^{2} /$ weight $)(0=$ normal weight (>18.5-25) (reference), 1=underweight $(\leq 18.5), 3=$ overweight $(>25-30), 4=$ obesity $(>30))$; only one participant was underweight and was removed; have children $(0=$ no biological children (reference), $1=$ have biological children); coffee use (1=no coffee (reference), 2=1-2 cups a day, $3=3-4$ cups a day; $4=\geq 5$ cups a day); and previous cancer $(0=$ no (reference), $1=$ yes $)$ at the time of interview.

\section{Statistical analysis}

Frequencies were used to describe the background and covariates of the study population. The differences between day and night workers were tested by $\chi^{2}$ test for categorical variables and t-test for continuous variables. In the analyses of associations, people with missing information on a specific covariate were excluded in the analyses including that covariate. Multiple Cox proportional hazard regression analyses for covariates were used to compute HRs with 95\% CIs. Exposure was defined as night work (or not) with a subdivision for duration of exposure. All individuals contributed with time until date of the first prostate cancer diagnosis or censoring. Censoring events included other cancer diagnosis during the follow-up, date of death or end of follow-up time $(31 / 12 / 2010)$, whichever came first. The analyses were adjusted for the statistical within-twin pair dependency.

The proportional hazards assumption was satisfied, which was examined by testing a model including an interaction between the night work (yes/no or categorised) and the survival time as a covariate. Potential familial confounding was controlled for, by analysing twin pairs discordant for prostate cancer (ie, one twin in a pair was diagnosed with prostate cancer during the follow-up, whereas the twin partner was not diagnosed). Conditional Cox proportional hazard regression was applied, where each twin pair was provided with their own baseline hazard. All analyses were performed using SAS V.9.4.

Some of the covariates had missing values, and we performed multiple imputations under the assumption that data were missing at random. The imputation was repeated 20 times using proc mi in SAS. The values of complete cases were compared with the imputed values, and only marginal deviations were observed.

\section{RESULTS}

The mean follow-up time was 8.7 years (range: $0-13$ ). The total number of person-years in the cohort when participants were censored after death, time of diagnosis or after 31 December 2010 was 107545 . Prostate cancer occurred in 454 men between baseline and the last day of the complete follow-up, and 538 men died during follow-up.

Background information is presented in table 1. Night workers were slightly younger, used more tobacco, were 
Table 1 Characteristics of the study population at baseline, N (\%)

\begin{tabular}{|c|c|c|c|}
\hline \multirow{3}{*}{ Age, years } & \multicolumn{2}{|l|}{ Number of indivi(duals (\%) } & \multirow[t]{2}{*}{ p Value } \\
\hline & Non-night workers $(n=7506)$ & Night workers $(n=4816)$ & \\
\hline & $51.7(4.7)$ & $51.2(4.8)$ & $<0.001$ \\
\hline Compulsory & $3069(41)$ & $2071(43)$ & \\
\hline More than compulsory & $4434(59)$ & $2744(57)$ & \\
\hline Children & & & 0.35 \\
\hline Have children & $6122(82)$ & $3960(82)$ & \\
\hline Do not have children & $1384(18)$ & $856(18)$ & \\
\hline Missing & - & - & \\
\hline Tobacco use & & & $<0.001$ \\
\hline Body mass index & & & $<0.001$ \\
\hline Normal weight & $3570(48)$ & $2099(42)$ & \\
\hline Underweight & $30(0.4)$ & $10(0.2)$ & \\
\hline Overweight & $3325(44)$ & $2278(47)$ & \\
\hline Obesity & $530(7)$ & $500(10)$ & \\
\hline Missing & $51(0.7)$ & $19(0.4)$ & \\
\hline Physical activity & & & 0.04 \\
\hline Moderate & $1968(26)$ & $1209(25)$ & \\
\hline Missing & $4016(53)$ & $2746(57)$ & \\
\hline Coffee consumption & & & $<0.001$ \\
\hline No coffee & $471(6)$ & $311(6)$ & \\
\hline $1-2$ cups a day & $1298(17)$ & $789(16)$ & \\
\hline $3-4$ cups a day & $2595(35)$ & $1437(30)$ & \\
\hline $5+$ cups a day & $3140(42)$ & $2272(47)$ & \\
\hline Missing & $2(0.03)$ & $7(0.2)$ & \\
\hline Previous cancer & & & 0.14 \\
\hline No & $7319(98)$ & $4716(98)$ & \\
\hline Yes & $187(2)$ & $100(2)$ & \\
\hline Missing & - & - & \\
\hline New cancer diagnosis during follow-up & & & 0.16 \\
\hline No cancer & $6870(92)$ & $4419(92)$ & \\
\hline Prostate & $294(4)$ & $160(3)$ & \\
\hline Other cancer & $342(4)$ & $237(5)$ & \\
\hline Time to prostate cancer diagnosis (years(SD)) & $5.8(2.7)$ & $6.1(2.7)$ & 0.24 \\
\hline
\end{tabular}

Significance levels based on t-tests or $\chi^{2}$ tests. 
Table 2 HRs for shift work exposure groups applying multiple Cox analysis for prediction of prostate cancer (no cancer as reference) after baseline among male night workers and with $95 \% \mathrm{Cl}$. Reference: non-exposed. $n=12322$, total number of cases $=454$

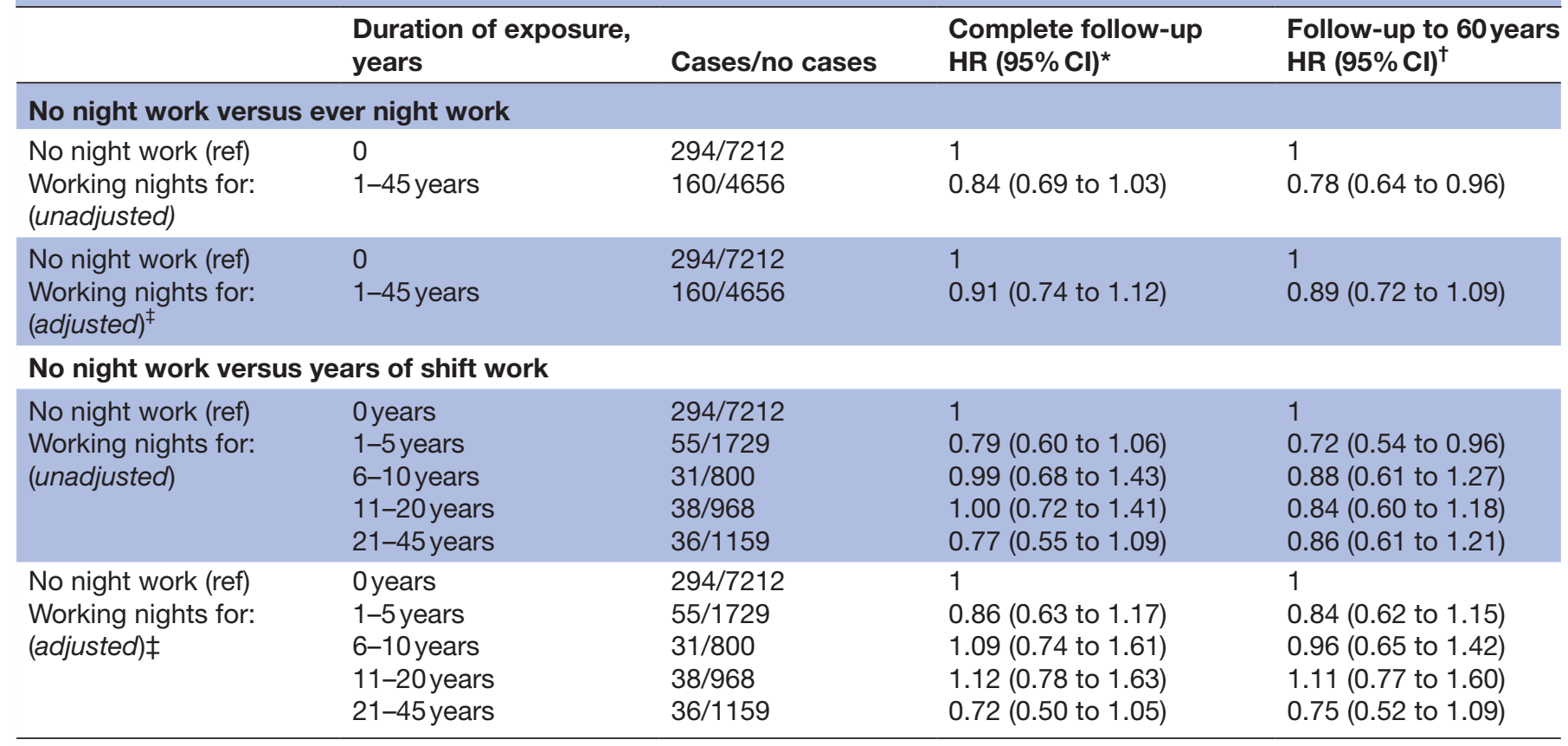

*Follow-up until 31 December 2010.

†Follow-up until the age of 60.

†Adjusted for: age + education level + tobacco consumption + BMI + having children + coffee consumption + previous cancer. $\mathrm{BMI}$, body mass index.

more overweight, consumed more coffee and did not differ from non-night workers on previous or later cancer or time to diagnosis of prostate cancer.

The cumulative incidence of prostate cancer was 3.3\% among the night workers and $3.9 \%$ among non-night workers $\left(\chi^{2}=3.66, p=0.16\right)$. Table 2 shows that the incidence was higher in the group with the highest exposure. Results of the Cox regression analyses, regardless of years of night work exposure, did not show any significant association to prostate cancer after adjustment for covariates (table 2). No association with duration of night work was seen. The analysis of twin pairs discordant for prostate cancer did not show any significant associations, irrespective of exposure duration (see table 3).

Table 2 Alcohol consumption was not entered into the main analysis, since the internal loss of data was $>50 \%$ for this variable. However, a separate analysis showed that the estimates with adjustment for alcohol was HR $=0.64(95 \%$ CI 0.40 to 1.03) for the exposure group with 21-45 hours of night work $(n=5444)$.

\section{DISCUSSION}

In this prospective cohort study of Swedish twins, we did not find any statistically significant association between the amount of night work and prostate cancer. Familial influences on the association were of minor importance. The results are similar to those of five previous studies, ${ }^{17-21}$ but at least three studies did show a significant association for 'ever night work' and prostate cancer. ${ }^{14-16}$ The present results add another negative finding to the previous five studies. Thus, six studies (including the present one) fail

Table 3 HRs for shift work exposure groups applying conditional Cox analysis of twin pairs discordant for prostate cancer (no cancer as reference) for prediction of prostate cancer after baseline among male night workers, and with $95 \% \mathrm{Cl}$. $\mathrm{n}=332$

\begin{tabular}{lllll}
\hline & $\begin{array}{l}\text { Duration of exposure, } \\
\text { years }\end{array}$ & $\mathbf{N ~ ( \% )}$ & $\begin{array}{l}\text { Complete follow-up } \\
\text { HR (95\% Cl)* }\end{array}$ & $\begin{array}{l}\text { Follow-up to 60years } \\
\text { HR (95\% Cl) }\end{array}$ \\
\hline No night work (ref) & 0years & $225(68)$ & 1 & 1 \\
Working nights for: & 1-5years & $42(13)$ & $1.02(0.48$ to 2.18) & $0.88(0.26$ to 2.46) \\
& 6-10years & $19(6)$ & $1.97(0.64$ to 6.02) & $1.24(0.26$ to 5.82) \\
& 11-20years & $22(7)$ & $0.88(0.32$ to 2.43) & $0.87(0.26$ to 2.93) \\
& 21-45years & $24(7)$ & $1.05(0.39$ to 2.84) & $0.57(0.13$ to 2.45) \\
\hline
\end{tabular}

${ }^{*}$ Follow-up until December 312010.

†Follow-up until the age of 60. 
to associate night work with prostate cancer, while three do not. This will move the meta-analytic HR of Rao $e t a l^{13}$ closer to unity and uncertainty. There is clearly a need for further studies on the present topic.

The discrepancy in results may be due to a lack of a common exposure metric, differences in the type of covariates adjusted for or heterogeneous occupational groups involved. Furthermore, selection into and out of night work occurs continuously, and this may attenuate any associations. It is also likely that the variability of results simply reflects a true lack of association between night work and prostate cancer. The present authors favour this latter explanation in view of the presently available data. Nevertheless, the issue of a potential association between night work and prostate cancer is far from settled.

It should be pointed out that also the association between night work and breast cancer in women is weak, even if meta-analyses in most cases produce significant results. ${ }^{8-12}$ Also regarding breast cancer, about half of the studies fail to find significant associations between night work and breast cancer, but the total number of studies is about twice that of the studies of prostate cancer.

The present study had some additional limitations. Thus, the sample had an intermediate size, exposure was self-reported and information on occupation/work task was not available. Furthermore, there was no possibility of estimating exposure to night work after the baseline measure. Another limitation is that the result concerned Swedish twins, which may limit generalisability. However, studies have shown that cumulative risks of cancer and mortality in twins do not differ from that in singletons. ${ }^{29}$ A strength of the study was the linkage of exposure at the individual level to nationwide register data through the social security number assigned to all persons living in Sweden. This resulted in an almost $100 \%$ complete follow-up of disease.

It is apparent that possible associations between night work and prostate cancer need to be studied in more detail. The present negative results add to the previous negative results, which dominate previously conducted studies. There is also a need for studies employing better research methods. This includes well-defined measurement of exposure, preferably using frequency of night shift in addition to duration of exposure. Future studies also need objective (company records) measures of exposure, rather than self-reported ones as well as repeated application of such measures. There is also a need for studying this in specific occupational groups.

To conclude, in this prospective study of Swedish twins, we found no evidence that night work, regardless of duration, is associated to prostate cancer. This agrees with the majority of the previous studies.

Contributors TÅ initiated the study, discussed the analyses and wrote the manuscript. JN discussed the design, carried out the analyses and commented on the manuscript. PS and KA discussed the design, supervised the analyses and commented on the manuscript. GK commented on the manuscript.
Funding This study was funded by the AFA Insurance Company (grant number 120264)

Competing interests None declared.

Ethics approval The Stockholm Region Ethical Review Board.

Provenance and peer review Not commissioned; externally peer reviewed.

Data sharing statement The data cannot be made publically available. According to the Swedish Ethical Review Act, The Personal Data Act and the Administrative Procedure Act, data can only be made available after legal review, for researchers who meet the criteria for access to this type of sensitive and confidential data. Readers may contact professor Kristina Alexanderson (Kristina.alexanderson@ki.se) regarding the data.

Open Access This is an Open Access article distributed in accordance with the Creative Commons Attribution Non Commercial (CC BY-NC 4.0) license, which permits others to distribute, remix, adapt, build upon this work non-commercially, and license their derivative works on different terms, provided the original work is properly cited and the use is non-commercial. See: http://creativecommons.org/ licenses/by-nc/4.0/

(C) Article author(s) (or their employer(s) unless otherwise stated in the text of the article) 2017. All rights reserved. No commercial use is permitted unless otherwise expressly granted.

\section{REFERENCES}

1. Ferlay J, Shin HR, Bray F, et al. Estimates of worldwide burden of Cancer in 2008: globocan 2008. Int J Cancer 2010;127:2893-917.

2. Jemal A, Siegel R, Ward E, et al. Cancer Statistics. 2009;59:225-49.

3. van Die MD, Bone KM, Williams SG, et al. Soy and soy isoflavones in prostate Cancer: a systematic review and meta-analysis of randomized controlled trials. BJU Int 2014;113:E119-E130.

4. Xu X, Cheng Y, Li S, et al. Dietary carrot consumption and the risk of prostate Cancer. Eur J Nutr 2014;53:1615-23.

5. Pukkala E, Martinsen JI, Weiderpass E, et al. Cancer incidence among firefighters: 45 years of follow-up in five nordic countries. Occup Environ Med 2014;71:398-404.

6. LeMasters GK, Genaidy AM, Succop P, et al. Cancer risk among firefighters: a review and meta-analysis of 32 studies. J Occup Environ Med 2006;48:1189-202.

7. Kolstad HA. Nightshift work and risk of breast Cancer and other cancers--a critical review of the epidemiologic evidence. Scand J Work Environ Health 2008;34:5-22.

8. Bonde JP, Hansen J, Kolstad HA, et al. Work at night and breast Cancer--report on evidence-based options for preventive actions. Scand J Work Environ Health 2012;38:380-90.

9. Jia Y, Lu Y, Wu K, et al. Does night work increase the risk of breast cancer? A systematic review and meta-analysis of epidemiological studies. Cancer Epidemiol 2013;37:197-206.

10. Wang F, Yeung KL, Chan WC, et al. A meta-analysis on doseresponse relationship between night shift work and the risk of breast Cancer. Ann Oncol 2013;24:2724-32.

11. ljaz S, Verbeek J, Seidler A, et al. Night-shift work and breast Cancer-a systematic review and meta-analysis. Scand J Work Environ Health 2013;39:431-47.

12. Kamdar BB, Tergas Al, Mateen FJ, et al. Night-shift work and risk of breast Cancer: a systematic review and meta-analysis. Breast Cancer Res Treat 2013;138:291-301.

13. Rao D, Yu H, Bai Y, et al. Does night-shift work increase the risk of prostate Cancer? a systematic review and meta-analysis. Onco Targets Ther 2015;8:2817-26.

14. Kubo T, Ozasa K, Mikami K, et al. Prospective cohort study of the risk of prostate Cancer among rotating-shift workers: findings from the Japan collaborative cohort study. Am J Epidemiol 2006;164:549-55.

15. Conlon $\mathrm{M}$, Lightfoot $\mathrm{N}$, Kreiger N. Rotating shift work and risk of prostate Cancer. Epidemiology 2007;18:182-3.

16. Parent MÉ, El-Zein M, Rousseau MC, et al. Night work and the risk of Cancer among men. Am J Epidemiol 2012;176:751-9.

17. Schwartzbaum J, Ahlbom A, Feychting M. Cohort study of Cancer risk among male and female shift workers. Scand J Work Environ Health 2007;33:336-43.

18. Kubo T, Oyama I, Nakamura T, et al. Industry-based retrospective cohort study of the risk of prostate Cancer among rotating-shift workers. Int J Urol 2011;18:206-11.

19. Gapstur SM, Diver WR, Stevens VL, et al. Work schedule, sleep duration, insomnia, and risk of fatal prostate Cancer. Am J Prev Med 2014;46(3 Suppl 1):S26-S33. 
20. Yong $\mathrm{M}$, Blettner $\mathrm{M}$, Emrich $\mathrm{K}$, et al. A retrospective cohort study of shift work and risk of incident Cancer among german male chemical workers. Scand J Work. Environ Health 2014;40:502-10.

21. Papantoniou K, Castaño-Vinyals G, Espinosa A, et al. Night shift work, chronotype and prostate Cancer risk in the MCC-Spain casecontrol study. Int J Cancer 2015;137:1147-57.

22. Stevens RG. Testing the light-at-night (LAN) theory for breast cancer causation. Chronobiol Int 2011;28:653-6.

23. Flynn-Evans EE, Stevens RG, Tabandeh $\mathrm{H}$, et al. Total visual blindness is protective against breast Cancer. Cancer Causes Control 2009;20:1753-6.

24. Melatonin BDE. Sleep disturbance and Cancer risk. Sleep Med Rev 2009;13:257-64.

25. Blask DE, Hill SM, Dauchy RT, et al. Circadian regulation of molecular, dietary, and metabolic signaling mechanisms of human breast Cancer growth by the nocturnal melatonin signal and the consequences of its disruption by light at night. $J$ Pineal Res 2011;51:259-69.

26. Filipski E, Delaunay F, King VM, et al. Effects of chronic jet lag on tumor progression in mice. Cancer Res 2004;64:7879-85.

27. Åkerstedt T, Knutsson A, Narusyte J, et al. Night work and breast Cancer in women: a swedish cohort study. BMJ Open 2015;5:e008127.

28. Lichtenstein P, De Faire U, Floderus B, et al. The Swedish Twin Registry: a unique resource for clinical, epidemiological and genetic studies. J Intern Med 2002;252:184-205.

29. Öberg S, Cnattingius S, Sandin S, et al. Twinship influence on morbidity and mortality across the lifespan. Int $J$ Epidemiol 2012;41:1002-9. 